\title{
Mapa das Cortes: perspectivas cartográficas
}

\begin{abstract}
Jorge Pimentel Cintra ${ }^{1}$
RESUMO: $\bigcirc$ presente trabalho realiza uma análise exaustiva do Mapa das Cortes, aplicando critérios da cartografia, em particular da cartografia matemática. Assim, analisam-se: autor, escala, projeção, meridiano de origem, cores, convenções, simbologia e outros. Após uma análise morfológica qualitativa, passa-se a um exame quantitativo, comparando esse mapa com um atual, bastante preciso: com o auxílio de um programa de cartografia digital e uma planilha eletrônica foram comparadas as coordenadas geográficas (latitude e longitude) de mais de 430 pontos. A quantificação sistemática e detalhada dos erros em diferentes regiões, da costa atlântica à região amazônica, mostrou aspectos surpreendentes de como o Mapa das Cortes (MC) foi habilmente construído. Essa análise permitiu quantificar de maneira mais precisa as distorções, identificando em que locais foram introduzidas e seu caráter indubitavelmente proposital.

PALAVRAS-ChAVE: Mapa das Cortes. Análise cartográfica. Análise quantitativa. Análise estatística.

ABSTRACT: In this paper, we present a thorough analysis of the Map of the Courts based on criteria used in cartography, particularly mathematical cartography. As such, it takes into account the following elements: author, scale, projection, the prime meridian, colors, conventions, symbology, and other. After a qualitative morphological analysis, we move on to a quantitative examination by comparing the said map with a quite accurate present-day chart, using a digital cartography software application and spreadsheet to match the geographic coordinates (latitude and longitude) of over 430 points. The systematic and detailed quantification of errors in various areas, from the Atlantic coast to the Amazon region, revealed surprising aspects as to how skillfully the Map of the Courts was constructed. This analysis enabled us to quantify the distortions more accurately and thus identify the locations where they were introduced as well their unquestionable intentional character.

KEY WORDS: Map of the Courts. Cartographic analysis. Quantitative analysis. Statistical analysis.
\end{abstract}

1. Docente da Escola Politécnica da Universidade de São Paulo. E-mail:<jpcintra@ usp.br>. 
2. No verso se lê: "C'est une copie conforme à l'original [...] Elle vient des dépots de Lisbonne". Embora se leia que é uma cópia, trata-se de um dos originais, como bem argumentaram Rio Branco e Jaime Cortesão.

3. Nessa minuta lê-se: "Serviu para ajustar o Tratado assinado em 1750 [...] linha vermelha que, por ser anterior ao tratado, não vai conforme com ele $[\ldots]$ ao seguir pelo Rio Negro até entrar no Uruguai $[\ldots]$ devia buscar a origem principal do Rio Ibicuí [...]".

4. "É cópia fiel e exata [...] linha vermelha que não vai conforme com ele (o Tratado) por $[. .$.$] buscar as cabe-$ ceiras do Rio Negro e seguir por ele $[\ldots]$ devendo buscar a origem principal do Rio Ibicuí [...]".

5. "Es copia fiel y exacta [...] linea encarnada [...]". Ou seja, não faz a ressalva, por a linha estar em plena conformidade com o Tratado.

6. Entre as mais próximas do Tratado, encontram-se, por exemplo, o chamado Mapa Borges de Castro, o Mapa do Rio de Janeiro e o Mapa da Biblioteca Pública Municipal do Porto.

7. Por exemplo, o acréscimo dos rios Nucorá, São João e Iriboba na Bacia do Paraná, além de uma inversão de posição do Uruguai-Pitã, que causou muitas dores de cabeça ao barão do Rio Branco na Questão de Palmas. Um dos erros grosseiros é o posicionamento do rio Beni como afluente ou formador do rio Xingu, ao invés de o ser do Madeira.

8. Nas cópias portuguesas abreviam-se as palavras Espanha e Meridional, colocadas por extenso nas cópias espanholas, que por sua vez abreviam o pronome que e omitem a primeira palavra da expressão Feita no anno de 1749.
Introdução

Em 1749, foram elaborados dois mapas idênticos para servirem de base para o Tratado de Madri (1750): um ficou com a Espanha, e o outro, com Portugal; este último foi encontrado em Paris pelo barão do Rio Branco². Esses mapas primitivos são identificáveis pelo trajeto da linha vermelha de fronteira ao sul e pelo teor da minuta contida no verso, chamada minuta $A^{3}$, adicionada depois da assinatura do Tratado. Nessa primeira versão do mapa, a linha ainda segue pelo rio Negro, em vez de seguir pelo lbicuí, como ficou acordado nas negociações.

A partir desses dois mapas primitivos, foram feitas três cópias em Lisboa (1751) e enviadas a Madri, mantendo os limites pelo rio Negro, por fidelidade ao desenho original, mas contendo no verso uma minuta $B^{4}$, esclarecedora da mudança ocorrida nas negociações com relação à dita linha. Está em português, com Silva Teles assinando em primeiro lugar. Atualmente essas três cópias pertencem à Mapoteca do Itamaraty.

Por seu turno, foram feitas outras três cópias em Madri e enviadas a Lisboa. Nelas se incluiu a minuta $C^{5}$, em castelhano, com José de Carvajal assinando em primeiro lugar. A particularidade é que a linha vermelha foi corrigida para adaptar-se à letra do Tratado, e assim deixa de seguir o rio Negro para internar-se pelo lbicuí.

Além disso, foram sendo feitas diversas cópias ${ }^{6}$, com ligeiras variações. Através das minutas constantes do verso ( $A, B$ ou $C$ ), consegue-se distinguir a filiação de cada uma (origem portuguesa ou espanhola), concorrendo para isso o diferente traçado da linha vermelha e, também, o fato de as cópias espanholas conterem um acréscimo na toponímia de diversos rios e alguns erros cartográficos grosseiros $^{7}$. Outro elemento para verificar a procedência são as pequenas diferenças na cartela, situada no canto inferior direito do mapa ${ }^{8}$.

No presente trabalho, foi utilizada uma cópia de origem espanhola (Figura 1), pertencente à Biblioteca Nacional, disponível em meio digital, arquivo do tipo TIFF, colorido (RGB), com resolução de 300 dpi e tamanho de 82,5 Mb.

Análise cartográfica preliminar

Autoria. O Mapa das Cortes não indica o autor nem o desenhista, prática corrente na cartográfica da época, mas, por todo o contexto, estava implícito que se tratava de um mapa de responsabilidade do governo português, com informações de diversas fontes, e que não importava muito quem eram os autores concretos. De qualquer forma, sabe-se que foi feito em Lisboa, sob a direção de Alexandre de Gusmão, negociador do Tratado, com base: em traçados e riscos de sertanistas (mormente para o 


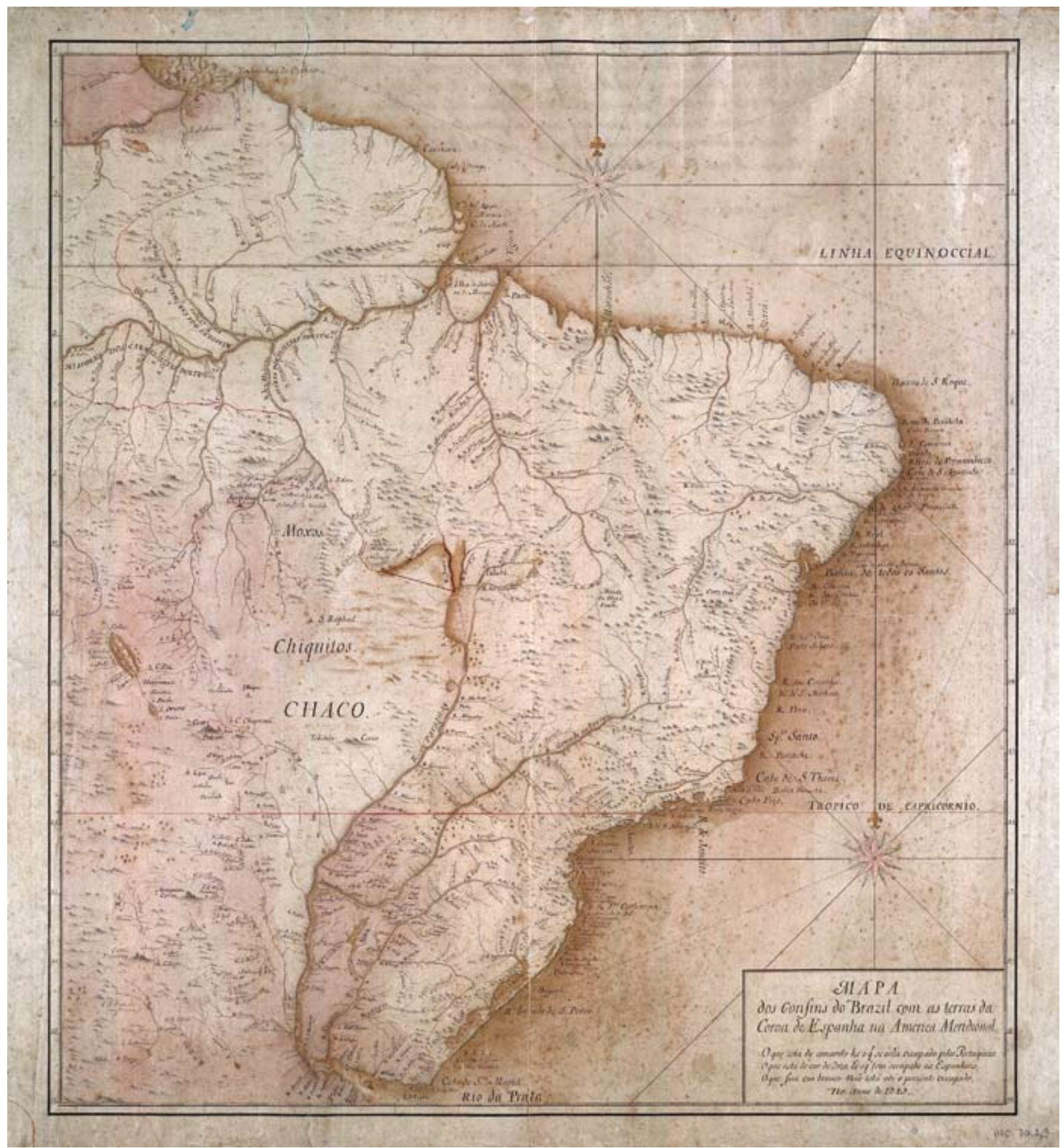

Figura 1 - Figura 1 - Mapa das Cortes (Mapa dos Confins do Brazil com as terras da Coroa de Espanha na América Meridional), 1749. Acervo da Fundação Biblioteca Nacional, Rio de Janeiro. 
9. Para a mesma dimensão horizontal do mapa, encontram-se - na borda superior, no equador e na borda inferior $(544 \mathrm{~mm})$ - diferentes valores de diferença da longitude: $40,9^{\circ}$ no paralelo superior; $40,8^{\circ}$ no equador; $\mathrm{e}$ $43,4^{\circ}$ no paralelo inferior.

10. A escala aproximada ao longo dos meridianos e do equador é de 1:8.000.000.

11. Convém que o meridiano de origem seja um observatório, pois nele se realizam observações astronômicas. Por exemplo, na época, observavam-se as ocultações dos satélites de Júpiter (notadamente Io) e construíam-se as tábuas com as previsões das ocultações dos mesmos Assim, é possível a sincronia e o cálculo da diferença horária entre o local do observatório e o local que se quer medir e infere-se facilmente a diferença de longitudes.

12. O meridiano de Paris situa-se a $2,33^{\circ}\left(2^{\circ}\right.$ e $\left.20^{\prime}\right)$ a leste de Greenwich, valor que deve ser somado para passar de uma referência à outra.

13. Foi feita através da conhecida Dissertação lida perante a Academia Real de Ciências de Paris, em 27 de novembro de 1720 . Esse autor teria utilizado as longitudes do cabo de Santo Agostinho $\left(36,33^{\circ}\right)$ de Santo Antão $\left(27,67^{\circ}\right)$, a oeste de Paris, resultando numa diferença de $8,67^{\circ}$ (na realidade, $9,17^{\circ}$ ), enquanto os mapas portugueses davam valores de $3^{\circ}, 2^{\circ}$ ou até menos. Esse valor é o que deveria corresponder às 370 léguas a oeste de Cabo Verde, da qual Santo Antão é a mais a oeste. É Cortesão quem indica que Delisle devia referir-se ao Cabo de Santo Agostinho, e acrescenta que utiliza duas observações feitas por Marcgraf de eclipses da Lua feitas na Ilha de Antonio Vaz (Recife). Isso não parece de todo correto, já que o cabo de Santo Agostinho está $0,3^{\circ}$ ao sul de Re traçado de rios do interior); em mapas das missões jesuíticas da América espanhola; no mapa de La Condamine (Bellin, 1760) para a região amazônica; e nos mapas e tábuas de coordenadas geográficas dos padres matemáticos, para parte da região costeira, entre outros.

Projeção e Escala. Essas duas informações básicas não constam do mapa e teria sido importante que constassem. À primeira vista, parece tratar-se de uma carta plana quadrada ou Plate carrée; isso porque as bordas graduadas (em princípio meridianos) e os meridianos das duas rosas dos ventos são perpendiculares ao equador e à linha do trópico. Verifica-se também a igualdade entre as graduações de longitude no equador e as de latitude nas duas bordas laterais. Mas há um elemento que desautoriza classificar essa projeção como carta plana quadrada: a graduação do paralelo inferior (latitude de $36^{\circ}$ ) possui um tamanho menor que as demais e o coeficiente de redução é de 0,94, ou seja, $6 \%$ menor. Através desse valor obtido pelo cálculo, foi possível eliminar algumas projeções, como a de Mercator ou uma Cônica, mas não foi possível, até o momento, identificar positivamente a projeção utilizada. Para efeitos práticos, o valor da redução foi aplicado aos valores obtidos nas medições de longitude?. Assim sendo, a escala métrica é constante ao longo do equador e dos meridianos ${ }^{10}$, mas não ao longo dos paralelos.

Meridiano de origem. Na medição de latitudes, o equador é a origem natural de contagem, não acontecendo o mesmo com as longitudes. É necessário, pois, escolher de forma relativamente arbitrária um meridiano de origem: de preferência um local com observatório ${ }^{11}$. Nessa época, nos mapas portugueses, eram utilizados indistintamente os meridianos de Paris ${ }^{12}$ e o da itha do Ferro (uma do arquipélago das Canárias), estando este último situado, para efeitos práticos, a exatos $20^{\circ}$ do primeiro, facilitando as conversões de um para outro. Como é sabido, o MC não indica a origem da contagem dos meridianos para evitar, pelo menos num primeiro momento, as discussões em torno da linha de Tordesilhas que é igualmente omitida. Uma das críticas de Delisle ${ }^{13}$, que desencadeou fortes reações da Espanha, é que os mapas portugueses deslocavam bastante a costa do Brasil (e o resto do território) em direção à África, colocando mais terras "para dentro" da linha de Tordesilhas.

No presente trabalho, foi feita uma tentativa de, através da análise das três escalas de longitudes, determinar o meridiano de origem desse mapa. Foram tomados como possíveis referências os meridianos: itha do Ferro, Lisboa, Londres e Paris; cada um fornece, para a longitude Rio de Janeiro, diferentes frações de grau, e o resultado mais aproximado, indica que pode tratar-se do meridiano de Paris contado para oeste ${ }^{14}$. Corrobora essa hipótese o fato de esse meridiano ter sido a origem das coordenadas medidas pelos padres matemáticos ${ }^{15}$, ainda que esses, tendo medido também a longitude do Rio de Janeiro, transformaram todos os seus dados para essa cidade, por simples subtração. 
Cores, convenções cartográficas, símbolos e outros detalhes. $\bigcirc$ mapa apresenta uma coloração geral sépia, acentuada pelo tempo. Como consta da minuta do verso, a linha de divisa contínua é de cor vermelha: inicia-se em Castilhos Grandes, ao sul, e termina ao norte na, nessa época, presumível e incerta divisa do Brasil com as antigas Guianas ${ }^{16}$. Existem leves aguadas para indicar áreas ocupadas por portugueses (amarelo) ou espanhóis (rosa), como diz a cartela ${ }^{17}$. Os dois meridianos extremos estão graduados de três em três graus, alternando-se, de grau em grau, em trechos escuros e claros. Essa alternância também se dá nas três graduações (equador e paralelos). A linha do trópico também está desenhada (em tom avermelhado), mas sem graduação. $\bigcirc$ interior dos rios de margem dupla, de lagos e de pântanos possui uma cor sépia mais intensa, como ocorre também na zona costeira. Há duas belas rosas-dos-ventos, ambas de mesmo desenho: uma acima da baía de São Luis e outra na altura de Paranaguá. Cada uma está composta por uma estrela exterior de 8 pontas em cor rosa e branco, e uma outra estrela, de fundo, em azul e branco; das extremidades da primeira partem linhas cheias nas direções principais: $\mathrm{N}, \mathrm{NE}$, etc., de $45^{\circ}$ em $45^{\circ}$; e das extremidades da outra saem linhas tracejadas intermediárias; uma flor de Liz (em tom sépia escuro) indica a direção norte. Não parece que estejam em posição geográfica relevante, ocupando simplesmente uma posição esteticamente conveniente. Os topônimos em solo brasileiro estão grafados em português da época, com algumas abreviações, enquanto os da América espanhola estão em castelhano, não sem uma certa contaminação do português; alguns nomes estão grafados totalmente em maiúsculas latinas: Linha equinoccial, Tropico de capricornio, as Missoes dos Carmelitas ou Jesuitas e principalmente o Chaco, cujas dimensões também geográficas, estão muito exageradas, bem como Chiquitos e Moxos (missões), para ocupar, como se verá, um espaço em branco deixado pelo deslocamento do Pantanal. Em um mapa moderno, seria de exigir uma legenda com as convenções cartográficas, que aí não existe, mas há o que se poderia chamar de simbologia natural: montanhas e cerros em perspectiva; pequenas lagoas (indicando uma região de lagos); conjunto de ávores para representar matas; conglomerado de pequenas ilhas para representar arquipélagos; formas circulares preenchidas de vermelho para indicar povoações, às vezes encimadas por bandeirolas (em geral correspondem a fortes) ou cruzes (nesse caso, missões) ou constituídas por uma pequena edificação coroada por uma cruz (nesse caso cidades ou vilas de certo porte, com igreja matriz). A colocação desses símbolos sofre pequenos deslocamentos com relação à posição real, para que ganhem destaque no entorno, recurso admissível em cartografia. cife e a observação de pelo menos um dos eclipses (a de 14 de abril de1642), ocorreu no forte Ceulen, foz do Potengi, no Rio Grande do Norte, uns $3^{\circ}$ ao norte, como atesta Moraes (1984, p. 1213).

14. Ou, o que é equivalente, para a fração do grau, ao meridiano da ilha do Ferro contado para leste.

15. Diogo Soares e Domingos Capassi tomaram como origem o meridiano de Paris, por disporem das tábuas de Cassini, elaboradas para esse observatório, com a previsão das efemérides dos satélites de Júpiter.

16. Nas cópias espanholas, o trecho dessa linha - aproximadamente leste-oeste - que vai do Madeira ao Javari é ondulada; já nas portuguesas, é uma reta perfeita. Nestas últimas, o rio Javari é desenhado e nomeado, saindo para fora das margens do desenho.

17. A indicação de áreas ocupadas aponta para o novo princípio em jogo, o do $u t i$ possidetis (as fronteiras devem permanecer assim como possuís), que seria adotado como regulador da divisão das terras. 
Análise morfológica qualitativa

Ao olhar para esse mapa, a reação espontânea é dizer que se trata de um mapa primitivo do Brasil: pelas cores, diferentes das usuais em mapas; pela ausência dos limites interiores; e por apresentar, em alguns locais, morfologia diferente das dos mapas atuais. Essa apreciação é verdadeira, ainda que alguma diferença morfológica seria de se esperar, em função de estar sendo utilizada uma projeção diferente das usuais na maioria dos atlas modernos. Mas, a simples comparação visual com um bom mapa do Brasil, mostra diferenças que não se explicam só por isso; por exemplo, a posição do Pantanal, situado no meridiano de Belém; a colocação de Recife como ponto extremo leste do Brasil le não o Cabo Branco); a forma vertical alongada da llha de Marajó e o desenho de duas baías inexistentes entre Belém e São Luís; a simplificação da costa norte entre esses dois locais, que na realidade é cheia de ilhas e pequenas reentrâncias; a simplificação da foz de diversos rios, notadamente os afluentes do Amazonas e do Paraguai, não contemplando, compreensivelmente, seus inúmeros braços; a direção quase vertical dos afluentes da margem direita do Amazonas, quando na realidade todos, a partir do Xingu, apresentam uma inclinação da ordem de $45^{\circ}$ em direção à nascente (sudoeste); o Madeira, cujo curso é desviado para leste e não para oeste como deveria ser; todos esses afluentes são também encurtados em latitude, fazendo com que as missões castelhanas entre Moxos e Santa Cruz de la Sierra estejam situadas mais ao norte da posição real; a linha Paraná-Paraguai está desviada para leste, fechando com a linha do Madeira-Mamoré-Jaurú no Pantanal; a linha Tocantins-Araguaia também está deslocada para leste. Por outro lado, grande parte dos rios do interior carece de detalhes ou, quando os têm, apresentam notáveis distorções com relação à forma, por provirem de relatos de sertanistas, que avaliavam distâncias por dias de percurso, daí se deduzindo latitudes e longitudes imprecisamente. Ainda com relação a rios, há inversões de alguns deles. como o Menim e o Tapicuru (na baía de São Luís) ou o Inhambupe com o Tapicuru (na atual Bahia). Erros de maior vulto são: a colocação do Beni como formador ou tributário do Purus e não do Madeira; a colocação do rio Parnahiba (Piauí) na baía de São Luís; a transformação de rios em braços de outros e erros no tamanho e importância relativa de afluentes, por exemplo, nos formadores do rio Paraná. Com relação às localidades (vilas, cidades, fortes), há muitas que são colocadas sem nome: quatro no vale do Paraíba do Sul (certamente Taubaté e Lorena estão dentre elas), outras na costa do Rio Grande do Sul (as diversas povoações ocupadas cada uma por 60 casais), algumas ao longo do Amazonas; alguns fortes possuem a letra F (de Forte) após o nome (Gurupá, Macapá), em função desse trecho ter sido copiado do mapa francês de La Condamine; algumas vilas do interior são destacadas em função da mineração: Cuiabá, Goyas (Velho), Mariana, Vila Rica (Ouro Preto), Vila do Príncipe (Cerro). 
Para trabalhar no meio digital, foi utilizado o programa Maplnfo. Isso possibilitou gerar diversas tabelas de coordenadas de pontos para compará-las com as coordenadas-padrão obtidas da Carta do Brasil ao milhonésimo, em 46 folhas, produzida pelo IBGE (1 995). Como o próprio nome indica, está na escala $1: 1.000 .000$, que é oito vezes maior, com mais detalhes e muito mais precisa que o MC. Os cálculos e análises estatísticas foram feitos em planilha Excel, com tese nula, de a média não ser estatisticamente igual a zero. Como medida da precisão, adotou-se o desvio-padrão das medidas; este, junto com a média, define um intervalo em que se situam $68 \%$ dos erros. os dados importados do Maplnfo. No total foram quantificadas as diferenças em 431 pontos, número suficiente para uma boa análise.

A primeira tarefa, quase um quebra-cabeça, foi o estabelecimento da correspondência entre os acidentes geográficos do MC e do Mapa atual, do IBGE. Uma vez identificados os pontos homólogos, bem definidos nos dois documentos cartográficos, passou-se à fase de demarcação desses pontos e à medição das duas coordenadas, latitude e longitude, sobre as duas fontes, utilizando-se o referido programa de cartografia digital. Foram geradas tabelas de diferenças de coordenadas (em latitude e longitude), gráficos e alguns indicadores estatísticos, que permitiram as diversas análises e a síntese final. Tomou-se como âncora ou ponto de referência para longitudes (valor zero) o meridiano do Rio de Janeiro (morro do Castelo); assim, o MC foi calibrado e teve suas coordenadas referenciadas a esse valor de partida, contando com pontos definidos pelo encontro das linhas verticais com o equador. Para comparação com os valores do mapa atual, somou-se a longitude do morro do Castelo com relação a Greenwich $\left(43,18^{\circ}\right)$. Para a comparação relativa ao meridiano de Tordesilhas (que não consta do $\mathrm{MC}$ ), adotou-se para ele o valor - $9^{\circ}$ em relação ao do Rio de Janeiro $\left(52,18^{\circ}\right.$ em relação a Greenwich), em função de ser uma boa estimativa para o valor fixado por Delisle, tido como fonte confiável para os espanhóis e, também, como a última palavra em cartografia na época do Tratado; e por passar a $0,5^{\circ}$ (aproximadamente) a oeste de Belém, cidade cuja posse os espanhóis não contestavam e por ser o local onde muitos imaginavam passar a famigerada linha.

Para a quantificação e testes ${ }^{18}$, o MC foi dividido em regiões, nomeadas e analisadas a seguir. A análise fica mais compreensível se acompanhada por uma cópia do Mapa das Cortes ou mesmo um mapa atual em escala conveniente.

\section{A costa atlântica}

Esta foi considerada do Oiapoque ao cabo de Santa Maria e itha Maldonado, e prolongada pelo estuário do Prata, incluindo Montevidéu, Buenos Aires e Colônia do Sacramento, extensão na qual foram coletadas as coordenadas de 117 pontos. Em latitude, não há erro sistemático, e a precisão dos resultados é $0,22^{\circ}$, valor que pode ser considerado bom para a época. Como é sabido, 
19. Essa magnitude dos erros coincide com a da amostra de 7 valores apresentada por Cortesão (1965, p. 195).

20. Esse valor, refeito e calculado por diversos caminhos, difere dos $4,5^{\circ}$ apresentados por Cortesão (1965, p. 251). Por outra parte, mais do que falar em uma "distensão da costa para leste", como que querendo aproximála da África (que não aparece no mapa), parece preferível fixar a costa leste e falar de uma distensão para oeste.

21. O meridiano de Tordesilhas situa-se, segundo os cálculos mais favoráveis a Portugal, a $48,52^{\circ}\left(48^{\circ} 31^{\prime}\right)$ a oeste de Greenwich, portanto, uns poucos quilômetros a oeste de Belém. Essa posição figura em mapas brasileiros, não acontecendo o mesmo nos espanhóis, que deslocam a linha para leste, chegando até São Luís. foi possível contar com coordenadas precisas, levantadas pelos padres matemáticos, desde a Colônia do Sacramento até o Cabo Frio; o resultado, só para esse trecho (28 pontos), mostrou uma precisão de $0,14^{\circ}$, resultado melhor que o do conjunto. Para a longitude, dividiu-se a região em quatro, em função da homogeneidade dos erros. A primeira, do cabo de São Roque ao cabo de Santa Maria (72 pontos), em que não há erro sistemático e a precisão é de $0,37^{\circ}$ - pior que o erro em latitude, como esperado em função da dificuldade muito maior para medir essa coordenada, mas valor bom para a época; a parte medida pelos padres matemáticos tem uma precisão um pouco melhor $\left(0,30^{\circ}\right)^{19}$. Isso significa que as coordenadas da costa brasileira em todo esse trecho seguem muito de perto os valores reais e coincidem com as calculadas pelos padres matemáticos e não seriam contestadas pelos espanhóis, na eventualidade desses dados virem a público. Na segunda região, do cabo ou baixos de São Roque até o Ceará, já a partir da Ponta de Galinhos (e rio Guamaré, RN) e até o rio Mundaú (CE), detecta-se que as longitudes apresentam um erro sistemático de $1,62^{\circ}$, com precisão de $0,1^{\circ}$. Isso significa que foi introduzida uma distensão consistente e invariável $\left(1,62^{\circ}\right)$ nesse trecho. A terceira região, que vai do rio Acaraú (Aquirás) ao Camocim (rio de São Francisco, no CE), apresenta erros de longitude que crescem gradativamente de $2,0^{\circ}$ a $2,5^{\circ}$, ou seja, nesse trecho é introduzida uma distensão adicional de mais $0,9^{\circ}$. A quarta região (32 pontos) vai do rio Camocim ao Cabo Orange (AM) e apresenta um erro sistemático médio de $3,2^{\circ}$, com precisão de $0,31^{\circ}$. Isso significa mais $0,7^{\circ}$ de nova distensão, e um total superior a $3^{\circ}$, valor que se atinge em Belém do Pará. Está, pois desvendada e quantificada a primeira distorção do MC: uma distensão de $3^{\circ}$ no total acumulado ${ }^{20} \mathrm{e}$ convenientemente distribuída ao longo da costa leste-oeste. Três argumentos descartam qualquer possibilidade desses erros serem fortuitos ou acidentais:

A precisão das coordenadas $\left(0,22^{\circ}\right.$ e $\left.0,37^{\circ}\right)$, indicando que os portugueses possuíam conhecimentos e técnicas para medir coordenadas e desenhar mapas com essa precisão, que não justifica erros da ordem de $3^{\circ}$;

O erro praticamente nulo, a menos de pequenas oscilações, do Cabo de Santa Maria ao Cabo de São Roque;

O fato de que cada determinação de coordenadas é independente das demais: um erro grande num ponto seria detectado nos seguintes e poderia ser corrigido. Ou seja, um erro crescente para oeste a partir do cabo de São Roque não pode ser obra do acaso. Além disso, esse deslocamento é muito conveniente, pois coloca a linha de Tordesilhas em consonância com o mapa de Delisle laproximadamente de Belém ao Rio Grande de São Pedro), situação repetida em diversos outros mapas da época, que reconhece perante a Espanha essa nova posição ao norte e ao sul e já não inclui a Colônia do Sacramento, como era praxe anterior, mas mesmo assim ainda é bastante favorável a Portugal com relação à posição real (meridiano passando por Laguna) ${ }^{21}$. $O$ valor do erro $\left(3^{\circ}\right)$ 
também coincide com o erro, acidental ou não, de La Condamine na região amazônica, como se verá.

\section{rio Amazonas e seus afluentes}

Entre os afluentes, deu-se particular destaque aos rios Negro e Madeira (incluindo as Missões dos jesuítas entre os moxos). Nessa região, o MC contou com o apoio do mapa de La Condamine, em princípio fora de suspeita para os espanhóis. Para a comparação das coordenadas desse rio, foram tomados 31 pontos (em geral a foz dos afluentes, fortes e aldeias) e adotou-se como ponto âncora das longitudes o meridiano de Belém do Pará para não acumular o erro de $3^{\circ}$ com relação ao Rio de Janeiro; assim, os novos erros passam a ser sobre Belém do Pará ou sobre Tordesilhas: os portugueses sabiam que, no avanço, os espanhóis iriam fixar-se sobre essa linha. A análise em latitude revelou não haver erro sistemático e uma precisão de $0,14^{\circ}$, com exceção da llha de Marajó, que está alongada de $0,7^{\circ}$ para o sul, erro que se reflete no Tocantins e demais rios abaixo dessa ilha. Revelou em longitudes que até Manaus não há erro sistemático, com uma precisão de $0,35^{\circ}$ (valor coerente com o resto do mapa); mas, a partir daí, há erros que vão crescendo sistematicamente em direção a oeste: $0,8^{\circ}$ no Purus e Coari; $1^{\circ}$ no Juruá; 1,5 no Jutaí; 1,7 em São Paulo de Olivença, para terminar com $2,4^{\circ}$ no Javari. Ora, esse novo erro (negativo) tem dois efeitos: diminui em $2,4^{\circ}$ a extensão da ocupação portuguesa na Amazônia a partir de Belém e desconta bastante os $3^{\circ}$ de erro nessa cidade, devolvendo as coordenadas ao seu valor quase correto (em termos absolutos) quando se entra em território espanhol (diferença de $0,6^{\circ}$ ).

É ilustrativa a comparação entre o MC e o de La Condamine. Esse mapa francês está graduado em horas na parte de cima e em graus na parte de baixo, sempre com relação ao meridiano de Paris. Foi copiado, em detalhes, pelo autor do MC, que, em alguns topônimos, sequer se deu ao trabalho de traduzir ou adaptar para o português. A semelhança se dá também nos erros: na forma alongada para o sul da ilha de Joanes ou Marayo; a forma dos rios (por exemplo, na curva do rio Guiriri, primeiro afluente do Xingu, da foz para a nascente); o tipo de letras (incluindo as maiúsculas para designar as missões), a maneira de simbolizar os fortes (e inclusive a colocação da letra F após o nome, que passa para o português). $\bigcirc \mathrm{MC}$ registra todas as localidades do mapa francês, ainda que não traga o nome em algumas (Pauxis, Aravida, Coari e outras). Através da comparação das coordenadas de 40 pontos comuns, chega-se à conclusão de que o MC é uma cópia bastante fiel do mapa de La Condamine ${ }^{22}$. Por sua vez, a análise específica do mapa desse cientista francês aponta alguns erros de falta de atenção ${ }^{23}$ e outros mais graves, mostrados a seguir. Centrando a atenção no curso do Amazonas, foram tomados 35 pontos bem distribuídos, tendo como referência o meridiano de Belém do Pará, em que as coordenadas absolutas de La Condamine estão muito boas (menos de 0,05 de erro). Em latitude, constata-se que não há erro sistemático e a precisão é de $0,15^{\circ}$; mas, em longitude, a
22. As diferenças são inferiores a $0,2^{\circ}$ nas duas coordenadas, não havendo erro sistemático em latitude, mas sim, em longitude: $0,2^{\circ}$, supondo coincidência e origem comum em Belém do Pará.

23. Por exemplo, a colocação dos valores de $55^{\circ} \mathrm{e} 60^{\circ}$ de graduação dos meridianos na posição correspondente ao $54^{\circ}$ e $59^{\circ}$; ou, ainda, a falta de colocação de nome em diversos locais, como Manaus e outros. Esse mapa traz também, em linha mais clara, o conhecido mapa do padre Fritz e os dizeres estabelecem uma patente comparação entre ambos, sugerindo erros no mapa desse jesuíta. De fato existem, mas nesse trecho são menores do que os do cientista francês. 
24. Para tentar explicar esse comportamento dos erros, deve-se ter em conta que La Condamine, segundo a sua Relação abreviada, só mediu a longitude em três pontos. Acertou nos dois extremos, Cuenca e Belém do Pará, e errou no intermediário, a foz do Napo. Esse erro de $3,1^{\circ}$ tornou o Amazonas mais curto do Napo a Belém e mais comprido na outra parte, deformando-se em toda a extensão. Pela forma como se vangloria dos resultados, parece que não percebeu o quão temerário é desenhar uma carta só com 3 pontos de longitude e sem ter feito uma confirmação da longitude, crucial, do Napo, como fez nos dois extremos. Por outro lado, como salienta Cortesão, seu comportamento deixa a desejar: sabe-se que foi contratado pelo rei de Portugal para os trabalhos de medição e, de vendo fornecer os resultados das medidas com o natural sigilo profissional, tornou-os públicos sem maiores consultas, em benefício das pretensões da França na América. Por isso a pendência pelo complemento de seu pagamento arrastou-se por muitos anos. $\mathrm{O}$ fato de ter sido pago por Portugal também tornaria seu mapa suspeito, numa pendência com a Espanha, se esta soubesse do fato.

25. Nessa cópia, baseada em original castelhano, o entroncamento erroneamente é do Mamoré com o Guaporé, pois o Beni deságua no Purus e o Madre de Dios não figura explicitamente.

26. Em latitude, os erros estão na faixa de $2,3^{\circ}$ a $5,3^{\circ} \mathrm{e}$ em longitude, de $2,6^{\circ}$ a $4,5^{\circ}$. O caso de Santa Cruz de la Sierra, com um erro aparente de $7,4^{\circ} \mathrm{em}$ latitude (para o norte) e $0,01^{\circ} \mathrm{em}$ longitude, explica-se em função da existência de povoação homônima, situação que se desfez mais tarde com a colocação dos acréscimos de La vieja e La nueva, para que situação complica-se: de Belém do Pará ao rio Madeira há um pequeno erro sistemático e uma precisão de $0,40^{\circ}$, admissíveis, também em função da indefinição gráfica de alguns acidentes geográficos; no entanto, a partir desse ponto vai havendo um erro que cresce sistematicamente: Manaus $\left(0,8^{\circ}\right)$, Purus $\left(1,2^{\circ}\right)$, Tefé $\left(1,4^{\circ}\right)$, Juruá $\left(1,7^{\circ}\right)$, Içá $\left(2,2^{\circ}\right)$, até chegar ao Javari com $2,8^{\circ}$, acumulados. Ou seja, o rio Amazonas (de Belém até a fronteira fica encurtado de uns $3^{\circ}$ ), compensando a dilatação de Belém sobre o Rio de Janeiro; ajuste favorável a Portugal, pois apresenta o território do vale amazônico como menor (mais curto na direção leste-oeste) do que na realidade é. Isso já era esperado, depois que se constatou que os dois mapas coincidem na comparação relativa. Mas surge um problema no mapa de La Condamine: dado que suas coordenadas de Belém são exatas, não existe uma compensação no Javari e esta deve ocorrer em algum ponto intermediário antes de chegar a Cuenca e Tarqui, local onde esse cientista havia efetuado precisas medições junto com Bouger, seu colega da Academia de Ciências da França. Rastreando as longitudes, têm-se os seguintes valores: o erro atinge o máximo na foz do rio Napo $\left(3,1^{\circ}\right)$, e vai diminuindo no Ucayali $\left(2,5^{\circ}\right)$, Tigre $\left(2,3^{\circ}\right)$, Pastaza $\left(2,1^{\circ}\right)$, Borja $\left(1,3^{\circ}\right)$, Jaen $\left(0,8^{\circ}\right)$, Cuenca e Quito $\left(0,5^{\circ}\right)$. Ou seja, o erro é descontado, aos poucos, na subida dos Andes ${ }^{24}$.

\section{A linha Madeira-Guaporé}

A peça chave para entender a deformação geral das divisas a oeste é começar examinando o deslocamento das minas de Cuiabá: $2,5^{\circ}$ para norte e $4^{\circ}$ para oeste, situando-se praticamente no meridiano de Belém (Tordesilhas). Isso arrasta consigo o Pantanal (que está na posição de Brasília) e as linhas de rios associadas: Guaporé, Madeira, Jauru, Paraguai e Paraná. Além disso, o deslocamento para o norte reduz a dimensão norte-sul da região amazônica pretendida pelos portugueses. Para quantificar as deformações na linha Madeira-Guaporé, foram tomados 25 pontos; da análise resultou que o rio Madeira (com coordenadas boas na sua foz e na barra do rio Abacaxis), em vez de seguir o curso sudoeste para montante, segue na direção sul por uns $2^{\circ} \mathrm{e}$ depois flete acentuadamente para sudeste (giro de $90^{\circ}$ ); valendo lembrar que se situa nesse trecho o ponto médio do Madeira, junto às primeiras cachoeiras, que era o ponto de inflexão da linha vermelha de divisa, que devia buscar o Javari segundo uma linha leste-oeste. Em função desse giro, os erros são enormes: em Villa Bella (local castelhano, sem nome no mapa), entroncamento do Madre de Dios, Beni e Mamoré25 (formando o Madeira), o erro é de 2, $6^{\circ}$ em latitude (colocado mais ao norte do que deveria estar) e 4,9 em longitude (colocado mais para leste, mais para dentro do Brasil); no verdadeiro ponto de encontro Mamoré-Guaporé, o erro em latitude cresce para $4^{\circ}$, mantendo-se a distorção em longitude. Esses valores influenciam nos grandes erros encontrados nas coordenadas das missões jesuíticas espanholas entre os índios moxos ${ }^{26}$. A seguir, o rio Guaporé dirige-se para sudeste, menos do que na realidade, resultando em 
um erro de 1,70 em latitude e 3,1 $1^{\circ}$ em longitude, na barra do rio Sararé, ponto por onde passa a linha vermelha vinda da boca do Jauru.

\section{A linha Paraná, Paraguai, Jauru}

A análise de 36 pontos mostrou que, em latitude, os erros (com alguma exceção) são relativamente pequenos $\left(0,33^{\circ}\right)$, não sistemáticos e não cumulativos, até o segundo rio Corrientes, por onde a linha vermelha de divisa entra no rio Paraguai; a partir daí, nota-se um erro sistemático, que vai crescendo até atingir $2^{\circ}$ na boca do Jauru, no início da linha que vai buscar o Sararé. Já em longitude, vão existindo erros bastante flutuantes, mas ligeiramente cumulativos para leste,

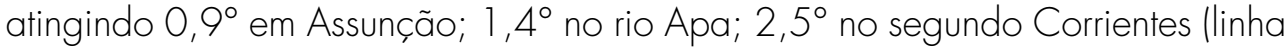
vermelha); 3,8 $8^{\circ}$ no Taquari; e 3,9 na boca do Jauru. Camapuã, povoação no caminho fluvial para Cuiabá, com erro quase nulo em latitude, apresenta erro de $3,1^{\circ}$ em longitude. As nascentes do Paraguai, Jauru e Guaporé são deslocadas, para o norte, de uns $7^{\circ}$, situação de compatibilidade com a diminuição da extensão norte-sul da bacia amazônica e, nesse trecho, com um encurtamento notável do Tapaiós e seus formadores (Juruena, Arinos e Teles Pires).

\section{América espanhola e missões}

Uma primeira região homogênea refere-se à Venezuela e às Guianas e inclui 14 pontos. Em latitude, os erros são pequenos na foz dos rios no Atlântico, mas crescem nos pontos interiores. Já em longitude, os erros acompanham aproximadamente os $3^{\circ}$ de Belém e situam-se na faixa de $2,5^{\circ}$ a $3,3^{\circ}$, havendo pontos no interior com erro de $4,8^{\circ}$. No resto da América (39 pontos) há não há erro sistemático e encontrou-se uma precisão de $0,41^{\circ}$, valor bastante natural por serem pontos cobrindo toda a extensão de norte a sul; a exceção são 5 pontos em torno de La Paz, com erro sistemático de $1^{\circ}$. Já em longitude, há um erro sistemático de $-1,0^{\circ}$ (para leste), com uma precisão baixa $\left(1,08^{\circ}\right)$. Pontos com erros grandes são, por exemplo, Cusco $\left(-4,09^{\circ}\right)$, Salta $\left(-2,48^{\circ}\right)$, Chuquisaca latual Sucre, com $-1,87^{\circ}$. Em separado, foram analisadas as missões jesuíticas no atual Rio Grande do Sul (São Borja, Santo Ângelo e outras), na região argentina de Misiones (S. Tomé, Santo Inácio e outras) e no Paraguai (S. Tiago, Fobati e outras), num total de 24 pontos. $\bigcirc$ resumo é que, para esses pontos, há pequenos erros sistemáticos e a precisão situa-se em torno de $0,4^{\circ}$, em ambas as coordenadas. Apesar de tudo, deve-se ter em conta que as coordenadas em território claramente espanhol pouco importam na disputa e devem ter sido tomadas de fonte espanhola, para evitar qualquer problema. Uma das fontes utilizadas deve ter sido o Mapa dos jesuítas denominado Paraquariae Provinciae Soc. Jesu cum adjacentib(us) novíssima descript(io), de 1732. Uma simples comparação visual já permite essa conclusão: há uma semelhança muito grande nos detalhes - formas geométricas, localidades representadas e limite ao sul se pudessem distinguir. Considerando que a povoação que se situa no mapa é a La vieja, o erro em latitude cai para menos de $1^{\circ}$ em cada coordenada. 
27. Esse valor, cerca de $4^{\circ}$, contrasta bastante com o valor fornecido por Cortesão (1965, p. 251), que é $9^{\circ}$. absolutamente coincidentes, além de uma linha vermelha de limites, não muito diferente ao sul e a oeste, até o Pantanal.

\section{Bacias e vilas interiores}

Aqui destacam-se as do Tocantins, São Francisco, Uruguai e Paraná. A bacia do Tocantins ( 13 pontos) fica condicionada pelos deslocamentos do Pantanal e de Belém. Como deve desaguar próximo de Belém ( $3^{\circ}$ de erro), vai sofrendo de norte a sul um desvio acentuado para a direita, a fim de ter suas nascentes próximas das bacias vizinhas que estão em posição correta e assim não deixar espaços vazios. Em função da posição do Pantanal, próximo do atual Distrito Federal, os afluentes da margem esquerda não têm espaço para descer e ficam encurtados de $4,1^{\circ} \mathrm{em}$ latitude. Em longitude, os desvios são para leste, chegando ao valor de $3,9^{\circ 27}$, em grande parte para compensar o erro de Belém. A direção real é muito próxima da linha norte-sul, enquanto o $M C$ apresenta uma inclinação de sudeste $\left(45^{\circ}\right)$ muito acentuada, para evitar a superposição com a região de Cuiabá.

Quanto às vilas, um grupo interessante é o conjunto de 14, do interior do país, com deslocamentos bastante variados: Moji e Curitiba apresentam erro quase nulo em ambas as coordenadas; Taubaté, Jundiaí, Cachoeira (Paulista) e São Paulo apresentam erro desprezível em latitude e um erro aceitável (até $0,6^{\circ}$ ) em longitude; outras apresentam erro em longitude da mesma ordem de grandeza, mas valores acentuados em latitude, como é o caso de Vila do Príncipe (Serro; $4,1^{\circ}$ ), Vila Rica (Ouro Preto; $\left.3,0^{\circ}\right)$ e Mariana $\left(2,8^{\circ}\right)$. Esses erros no interior não influem na avaliação de fronteiras e estão coerentes com o erro no rio Doce, que, no $M C$, sobe, e deveria descer. Meia Ponte (Pirenópolis) também segue o erro do contexto, que é o desvio da bacia do Tocantins para a direita. Mas existem alguns casos que merecem destaque por sua intencionalidade e magnitude. Em primeiro lugar, Goiás [Velho], que apresenta erro muito grande em relação à posição real: está situado muito ao norte $\left(5,2^{\circ}\right)$ e muito a leste $\left(4,7^{\circ}\right)$, no atual sertão da Bahia, erro esse que, numa cartografia que procurasse a exatidão, não seria de esperar, por duas razões principais:

Por se contar com coordenadas medidas pelos padres matemáticos, que em geral são muito boas (ainda que, neste caso concreto, há um erro de 1,70 em longitude; pouco com relação aos 4,70); e

Por estar colocado junto ao afluente mais a leste do Tocantins, quando se sabe (e se sabia na época) que sua posição é nas margens do rio Vermelho, um dos afluentes do Araguaia; mas, nesse caso, pela colocação deste último, ficaria bem a oeste do meridiano de Tordesilhas e a oeste mesmo de Cuiabá. Ou seja, pelas deformações gerais introduzidas no mapa, tinha mesmo que ser deslocada para leste, com sua posição sendo fixada com relação a Cuiabá, sem se importar com outras considerações. Vale repisar que Cuiabá, possível pomo de 
discórdia, sofre um deslocamento de 2,50 para norte e 4,0 $0^{\circ}$ para leste e assim situa-se dentro da linha de Tordesilhas $\left(0,1^{\circ}\right)^{28}$. $\bigcirc$ local de Vila Bela da Trindade (zona de mineração, MT), com um deslocamento de 1,8 para o norte e $3,1^{\circ}$ para leste, fica sendo a única mineração contestável, colocada claramente em território espanhol.

Já a bacia do São Francisco sofre uma distorção suficiente para acompanhar a deformação da costa que vai do Rio Grande do Norte a Belém do Pará, ou seja, uma distensão de $3^{\circ}$ no trecho quase horizontal desse rio que, no mapa, só tem um afluente (não identificado).

Outro grupo de pontos situa-se na bacia Uruguai-Paraná: são 46 pontos determinados pela barra dos afluentes. Em latitude não há erro sistemático, mas a precisão é de $0,6^{\circ}$; em longitude, há um erro sistemático de $0,5^{\circ}$, para oeste e uma precisão de $0,8^{\circ}$. Para a maioria desses pontos, não há coordenadas determinadas astronomicamente, mas só estimativas por distâncias percorridas a pé ou em canoa. Assim, muito fora de posição, há alguns rios que são os responsáveis por esses valores que diminuem a precisão da média. São eles: Piqueri, Iguatemi, Ivinhema, Paranapanema (ruins nas duas coordenadas), Pardo, Verde, Sucuruí, Tietê, Grande, Moji-Pardo (esses, em longitude); além de erros, na casa dos $3^{\circ}$, nas nascentes dessa bacia. Erros de toponímia são: chamar de rio Grande o que é o Paranaíba, e de Sapucaí o que é o Grande; o Pardo é substituído pelo seu afluente Moji.

\section{Comparação com outros mapas}

$\bigcirc$ confronto com outras fontes cartográficas anteriores é mais um argumento que confirma a intencionalidade dos erros. Em primeiro lugar, tem-se o mapa solicitado por Alexandre de Gusmão a Freire de Andrade, denominado Descripçam do Continente da América Meridional... de 1746 lque foi o primeiro esboço do MC). Esse, em contraposição ao MC, apresenta um curso muito mais próximo do real para os rios Tocantins-Araguaia, Madeira-Mamoré-Guaporé, e também situa o Pantanal em posição mais acertada. E, quanto à descrição, sugere uma divisão entre as duas coroas próxima da que foi acertada no texto do Tratado.

Depois, o Mapa de Jean Baptiste Bourguignon D'Anville, de 1748, encomendado por Portugal e feito com as informações que the foram fornecidas. Neste mapa, anterior ao MC, há informações melhores (São Francisco, Madeira, Mamoré, Grande e Paranaíba), coordenadas muito mais precisas, e algumas delas cruciais, como a da boca do Jauru, as do Pantanal lquase na posição correta), Goiás (a 1,50 a oeste da linha de Tordesilhas e não 6,50 a leste como no MC), Cuiabá (5 $5^{\circ}$ a oeste dessa linha, e não $0,5^{\circ}$ a leste). Ou seja, a informação havia, mas não convinha representá-la no MC. Além disso, uma linha
28. Esse erro de $4^{\circ}$ é o que se verifica nas coordenadas absolutas (contas em referência ao Rio de Janeiro). Se a conta for sobrefeita em relação a Tordesilhas (âncora em Belém), o que parece preferível, a diferença vai para $7,6^{\circ}$, mais próxima dos $9^{\circ}$ fornecidos por Cortesão (1965, p. 251) 
verde já ensaiava uma divisão Portugal-Espanha, mostrando que os portugueses já a estudavam bem antes do Tratado.

\section{Conclusão}

presente trabalho, combinando cartografia histórica com cartografia digital, permitiu quantificar as distorções em mais de 430 pontos e concluir, com certeza estatística, que o mapa contém erros propositais em pontos estratégicos. Em resumo, um aumento de $3^{\circ}$ para oeste, do cabo de São Roque a Belém, aproveitando-se de um erro de mesma magnitude e em sentido contrário, intencional ou não, de La Condamine, que encurta o vale amazônico; outro que desloca Cuiabá (e o Pantanal) 2,50 para norte e $4^{\circ}$ para leste, com a consequente alteração nos cursos do Madeira-Mamoré-Guaporé, do Paraguai-Jauru, do Tocantins-Araguaia, causando um estreitamento do vale amazônico e trazendo boa parte da região oeste para dentro da imaginária Tordesilhas que passava na altura de Belém. Com esse deslocamento para oeste, o espaço aberto em território espanhol é preenchido pelo Chaco (pouco conhecido em dimensões) e pelas missões (Chiquitos e Moxos), cuja grafia, em letra de tamanho absolutamente desproporcional, ajuda a ocupar os espaços vazios. Minimizava-se, assim, toda a área pretendida por Portugal que ultrapassava os limites de Tordesilhas, facilitando uma troca de áreas (já latente nas negociações), envolvendo a Colônia do Sacramento. Esse mapa combinava os princípios de seguir as fronteiras naturais (rios e montanhas) e o das ocupações efetivas (uti possidetis) com uma montagem cartográfica que unia habilmente dados e cartas conhecidas e confiáveis para os espanhóis, a fim de causar uma impressão diminuída das áreas pretendidas pelos portugueses, coisa que se conseguiu num primeiro momento, a ponto de alguém ter denominado maliciosamente esse documento com o título: "Mapa das Cortes ou de como os portugueses enganaram os espanhóis com a ajuda de um brasileiro (Alexandre de Gusmão)".

De fato, a mentira ou a conveniência não poderia durar muito: as expedições demarcatórias iriam apontar as diferenças, o que levou, junto com outros fatores, à anulação do Tratado. Alexandre de Gusmão, em 1750, curava-se em saúde ao dizer que o documento cartográfico era mera referência, simples apoio visual, e o que valia de fato eram as descrições de acidentes geográficos constantes no texto do Tratado. 


\section{REFERÊNCIAS}

LIVROS

CORTESÃO, J. Alexandre de Gusmão e o Tratado de Madrid, 2. São Paulo: Imprensa Oficial; Fundação Alexandre de Gusmão, 2006.

História do Brasil nos velbos mapas. Rio de Janeiro: Instituto Rio Branco do Ministério das Relações Exteriores, 1965.

LA CONDAMINE, Charles Marie de, Relation Abrégée d'un Voyage fait dans l'interieur de l'Amérique Méridionale depuis la Côte de la Mer du Sud, jusqu'aux Côtes du Brésil E de la Guiane, en descendant la Riviere des Amazones; lûe à l'Assemblée publique de l'Académie des Sciences, le 28. Avril 1745. Avec une Carte du Maragnon, ou de la Riviere des Amazones, levée par le même, Paris: Veuve Pissot, 1745. Disponível em <http://books.google.com>. [ed. bras.: Viagem na América Meridional descendo o Rio das Amazonas (1745). Brasília: Senado Federal, 2000].

MORAES, Abrahão de. A astronomia no Brasil. São Paulo: Edusp; Instituto Astronômico e Geofísico, 1984

MAPAS

BELLIN, J. N. Carte du cours du Maragnon ou la grande rivière des Amazones dans sa partie navigable depuis Jaén de Bracamoros jusqu'à son embouchure et qui comprend la Province de Quito, et la Côte de la Guiane depuis le Cap de Nord jusqu'à Essequebé / levée en 1743 et 1744, et assujettie aux observations astronomiques par M. de la Condamine, de l'Ac. Rle. des Sc. augmentée du cours de la riviére Noire, et d'autres détails tirés de divers mémoires et routiers manuscrits de voyageurs modernes. 1760.1 Mapa. $17,5 \times 37,9 \mathrm{~cm}$ in folio $25,7 \times 40,0$ $\mathrm{cm}$. Escala: [ca. 1:11,000,000], 100 nautical leagues of 20 to the degree $=[4,95 \mathrm{~cm}]$. Disponível na John Carter Brown Library, Brown University: <http://jcb.lunaimaging.com>.

MAPA das Cortes (1749). Lisboa: Biblioteca Nacional, arquivo cart1004807.sid

IBGE. Mapa da Amazônia Legal. Rio de Janeiro: Instituto Brasileiro de Geografia e Estatística,1995. Disponível em: <ftp://geoftp.ibge.gov.br/ mapas/tematicos>.

\section{SITE DE REFERÊNCIA}

A CARTOGRAFIA do Brasil nas Coleções da Biblioteca Nacional (1700-1822). Para obter cópia pública dos mapas de La Condamine, Jean Baptiste Bourguignon d' Anville, Guillaume Delisle, Paraquariae Provinciae Soc. Jesu cum adjacentib (us) novíssima descript(io) e outros. Disponível em <http://purl.pt/103/1/catalogo-digital/autores.html>. Para obter diretamente o Mapa das Cortes, na cópia de José Monteiro de Carvalho, com boa resolução: <http://purl. pt/859>.

Artigo apresentado em 8/2008. Aprovado em 3/2009.

Annals of Museu Paulista. v. 17. n.2. July - Dec. 2009. 